\title{
Altered Expression and Function of Mitochondrial $\beta$-Oxidation Enzymes in Juvenile Intrauterine-Growth-Retarded Rat Skeletal Muscle
}

\author{
ROBERT H. LANE, DAVID E. KELLEY, VLADIMIR H. RITOV, ANNA E. TSIRKA, AND \\ ELISA M. GRUETZMACHER
}

\begin{abstract}
Department of Pediatrics, UCLA School of Medicine, Mattel Children's Hospital at UCLA, Los Angeles, California 90095, U.S.A. [R.H.L.]; and Departments of Internal Medicine [D.E.K., V.H.R.] and Pediatrics [R.H.L., A.E.T., E.M.G.], University of Pittsburgh School of Medicine, Magee-Womens Research Institute, Pittsburgh, Pennsylvania 15213, U.S.A.
\end{abstract}

\begin{abstract}
ABST
Uteroplacental insufficiency and subsequent intrauterine
growth retardation (IUGR) affects postnatal metabolism. In ju-
venile rats, IUGR alters skeletal muscle mitochondrial gene
expression and reduces mitochondrial NAD ${ }^{+}$NADH ratios, both
of which affect $\beta$-oxidation flux. We therefore hypothesized that
gene expression and function of mitochondrial $\beta$-oxidation en-
zymes would be altered in juvenile IUGR skeletal muscle. To test
this hypothesis, mRNA levels of five key mitochondrial enzymes
(carnitine palmitoyltransferase I, trifunctional protein of $\beta$-oxi-
dation, uncoupling protein-3, isocitrate dehydrogenase, and mi-
tochondrial malate dehydrogenase) and intramuscular triglycer-
ides were quantified in $21-d$-old (preweaning) IUGR and control
rat skeletal muscle. In isolated skeletal muscle mitochondria,
enzyme function of the trifunctional protein of $\beta$-oxidation and
isocitrate dehydrogenase were measured because both enzymes
compete for mitochondrial NAD ${ }^{+}$. Carnitine palmitoyltrans-
ferase I, the trifunctional protein of $\beta$-oxidation, and uncoupling
protein 3 mRNA levels were significantly increased in IUGR
skeletal muscle, whereas mRNA levels of isocitrate dehydroge-
nase and mitochondrial malate dehydrogenase were unchanged.
Similarly, trifunctional protein of $\beta$-oxidation activity was in-
\end{abstract}
creased in IUGR skeletal muscle mitochondria, and isocitrate dehydrogenase activity was unchanged. Interestingly, skeletal muscle triglycerides were significantly increased in IUGR skeletal muscle. We conclude that uteroplacental insufficiency alters IUGR skeletal muscle mitochondrial lipid metabolism, and we speculate that the changes observed in this study play a role in the long-term morbidity associated with IUGR. (Pediatr Res 50: 83-90, 2001)

Abbreviations
CPTI, carnitine palmitoyltransferase I
IUGR, intrauterine growth retardation
AGA, appropriate for gestational age
ICD, isocitrate dehydrogenase
MMD, mitochondrial malate dehydrogenase
ND-4L, NADH-ubiquinone oxidoreductase subunit 4L
HADH, trifunctional protein of $\beta$-oxidation
HADHA, trifunctional protein of $\beta$-oxidation $\alpha$ subunit
UCP3, uncoupling protein 3
UCP31, uncoupling protein 3 -long isoform
UCP3s, uncoupling protein 3 - short isoform

Uteroplacental insufficiency causes IUGR and is causally related to the development of multiple adult morbidities including insulin resistance, hypertension, coronary heart disease, and dyslipidemia (1). Although the effects of these pathophysiologies are most critically felt during adulthood, evidence exists that metabolism may already be altered in IUGR infants.

Received September 18, 2000; accepted February 23, 2001.

Correspondence: Robert Lane, M.D., Mattel Children's Hospital @ UCLA, B2-375 MDCC, 10833 Le Conte Avenue, Los Angeles, CA, 90095, U.S.A.; e-mail: rlane@mednet.ucla.edu

This research was supported, in part, by National Institute of Child Health and Human Development grants P30HD-28836-05 (R.H.L.), 1KO8BD01225-01 (R.H.L.), and 5P30DK46204-05 (R.H.L.), and the Magee-Womens Hospital Twenty-Five Club.
Several investigators have demonstrated that IUGR infants expend more energy and consume more oxygen than AGA infants (2-6); moreover, Bohler et al. (3) found a significant decrease in the respiratory quotient of IUGR infants, but not AGA infants, over the first 8 wk of life. Similarly, Chessex et al. (6) found increased lipid oxidation in 3- to 4-wk-old IUGR infants. The molecular mechanisms of how the transient in utero event of uteroplacental insufficiency affects IUGR postnatal metabolism are unknown.

Skeletal muscle mitochondrial metabolism contributes significantly to energy expenditure, oxygen consumption, and lipid oxidation. We have previously demonstrated that uteroplacental insufficiency leads to altered skeletal muscle mito- 
chondrial gene expression and metabolism in juvenile IUGR rats (7). IUGR rat skeletal muscle is characterized by reduced mitochondrial $\mathrm{NAD}^{+} / \mathrm{NADH}$ ratios and decreased ND-4L mRNA levels (7). ND-4L is a necessary component of the mitochondrial respiratory chain complex I. These finding are intriguing because $\mathrm{NAD}^{+}$is believed to be rapidly recycled between complex I of the respiratory chain and the mitochondrial HADH (Fig. 1) (8).

HADH is an inner mitochondrial membrane protein that contributes three of the four reactions necessary for mitochondrial long-chain fatty acid $\beta$-oxidation, including the reduction of $\mathrm{NAD}^{+}$to NADH (9). HADH competes directly for $\mathrm{NAD}^{+}$ with the Krebs cycle dehydrogenases ICD and MMD. As a result, this intramitochondrial competition is a potential point of flux control connecting the Krebs cycle and $\beta$-oxidation, which may be particularly important in skeletal muscle $(10$, 11).

CPTI and UCP 3 also affect mitochondrial $\beta$-oxidation flux $(12,13)$. CPTI catalyzes the exchange of acyl-carnitines across the mitochondrial outer membrane. UCP3 catalyzes mitochondrial proton leak and is preferentially expressed in skeletal muscle (14). Increased substrate flux through skeletal muscle mitochondrial $\beta$-oxidation is associated with increased UCP3 mRNA levels (15).

We therefore hypothesized that induction of IUGR in rats by maternal uteroplacental insufficiency would increase gene expression and function of HADH as well as gene expression of CPTI and UCP3, while not affecting the Krebs cycle dehydrogenases ICD and MMD. To test this hypothesis, we used a well-characterized rat model of uteroplacental insufficiency and IUGR that is induced by ligating both uterine arteries of the pregnant rat. Fetal and neonatal rats in this model are significantly lighter than controls that undergo identical anesthesia and sham surgery, and litter size does not differ between control and IUGR groups $(7,16)$. Like the human, the IUGR rat fetus is characterized by hypoxia, acidosis, hypoglycemia, and hypoinsulinemia $(16,17)$. These values normalize in the perinatal period (18). At d 21 of life, both male and female IUGR rats weigh significantly less than sham-operated control counterparts (7). Fasting serum triglyceride levels in 21-d-old (preweaning) control and IUGR rats are $90 \pm 10$ and $125 \pm 24$ $\mathrm{mg} / \mathrm{dL}$, respectively (19).

We quantified mRNA levels of CPTI (muscle isoform), HADHA, MMD, ICD, UCP3 in whole skeletal muscle, and enzyme function of HADH and ICD in skeletal muscle mitochondria from 21-d-old sham-operated control and IUGR rats (preweaning). We also measured skeletal muscle triglyceride levels in both IUGR and sham-operated animals because altered intramuscular triglycerides have been associated with dysregulation of skeletal muscle mitochondrial metabolism (20).

\section{METHODS}

Animals. All procedures were approved by the Institutional Animal Care and Use Committee of the Magee-Womens Research Institute, Pittsburgh, PA, U.S.A.

Timed pregnant Sprague Dawley rats (Taconic Farms Inc., Germantown, NY, U.S.A.) were housed in individual cages and were exposed to 12-h light-dark cycles. All animals were fed routine Purina rat chow ad libitum. The animals were allowed at least $2 \mathrm{~d}$ of acclimatization before experimental handling.

On d 19 of gestation (term is $21.5 \mathrm{~d}$ ), the maternal rats were anesthetized with intraperitoneal xylazine $(8 \mathrm{mg} / \mathrm{kg})$ and ketamine $(40 \mathrm{mg} / \mathrm{kg})$, and both inferior uterine arteries were ligated (IUGR) ( $n=12$ litters). Sham surgery was performed upon control animals who underwent identical anesthetic and surgical procedures except for the uterine artery ligation $(n=$ 12 litters). Maternal rats recovered within a few hours and had ad libitum access to food and water. The rats were allowed to delivery spontaneously, and the litter size was randomly culled to six at birth in both control and IUGR litters by veterinary staff who were blinded to the group and the purpose of the study. Maternal rats were allowed ad libitum access to food and water, and pups remained with their dams until d 21 of life.

To perform studies upon d 21 skeletal muscle, pups were separated from their dams for $4 \mathrm{~h}$ (to minimize individual

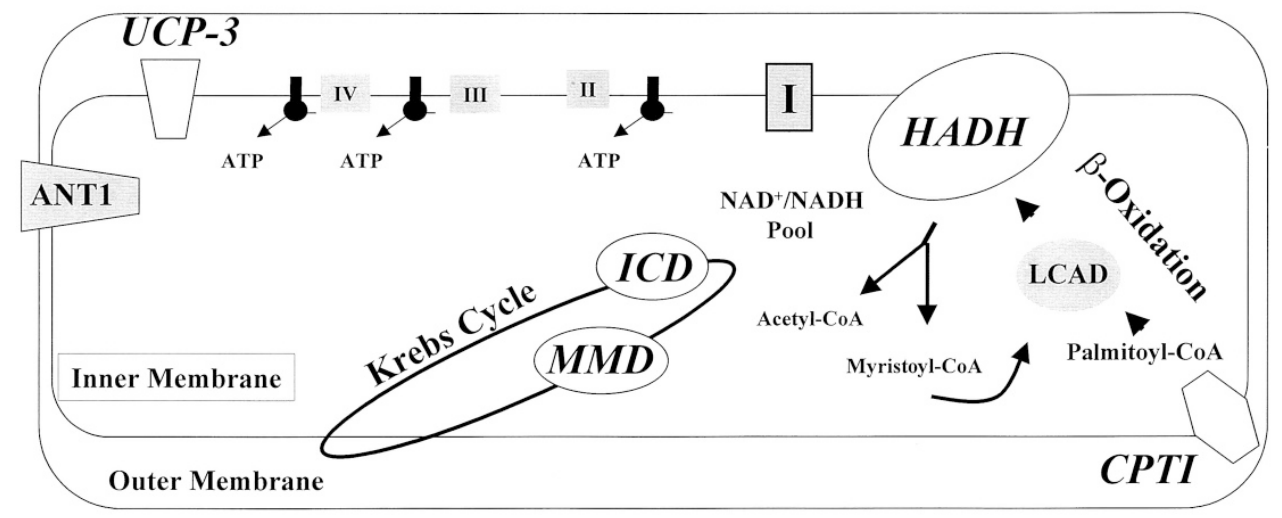

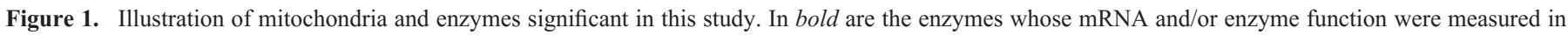

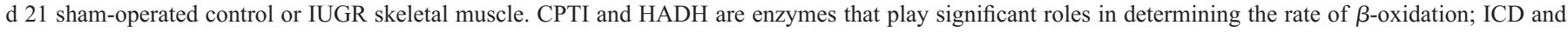

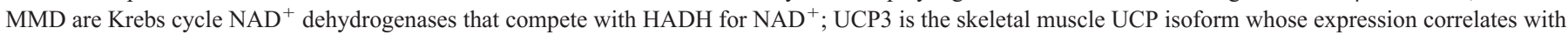

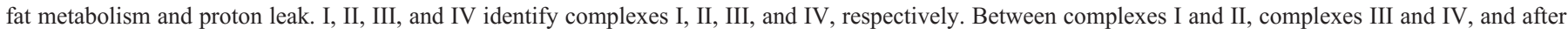
complex IV are representations of $\mathrm{F}_{0} \mathrm{~F}_{1}$ ATP synthase. $\mathrm{F}_{1}$ ATP synthase production of ATP is powered by proton flow through the $\mathrm{F}_{0}$ channel. 
hormonal variations associated with feeding) and sedated with isoflurane inhalation just before being killed. Whole hind limb muscle was isolated and either immediately frozen for RNA isolation and triglyceride quantification $(n=6$ litters each) or placed into mitochondrial isolation buffer (see below) $(n=6$ litters each).

$\boldsymbol{R N A}$ isolation. Total RNA was extracted from skeletal muscle by the method of Chomczynksi and Sacchi (21) and quantified in triplicate using UV absorbance at $260 \mathrm{~nm}$. Gel electrophoresis confirmed the integrity of the samples. Bovine retinal RNA was prepared in a similar manner.

Reverse transcriptase PCR. This methodology of reverse transcriptase PCR (RT-PCR) has been previously reported (7, $19,22,23)$. cDNA was synthesized using random hexamers and SUPERSCRIPT II RT (Life Technologies Inc., Gaithersburg, MD) from $1.0 \mu \mathrm{g}$ of skeletal muscle RNA added to 0.01 $\mu \mathrm{g}$ of bovine retinal RNA. The resulting cDNA was resuspended in $20 \mu \mathrm{L}$ of water, diluted into 1:100 aliquots, and stored at $-20^{\circ} \mathrm{C}$ until use. Three animals from each litter were used, and data from each litter was averaged and considered an $n=1$. For RT-PCR data, six litters were used for an $n=6$.

Amplification primers for CPTI, HADHA, ICD, MMD, UCP3s, UCP31, and rhodopsin are listed in Table 1. Primer sequences for the UCP isoforms were based upon human proteins. Each reaction was carried out in a total volume of 20 $\mu \mathrm{L}$ using $5 \mu \mathrm{L}$ of diluted RT reaction product, $20-30 \mathrm{pM}$ of rhodopsin primers, $10-50 \mathrm{pM}$ of target primers (CPTI, HADHA, ICD, MMD, UCP3s UCP31), $50 \mathrm{mM} \mathrm{KCl}, 10 \mathrm{mM}$ Tris- $\mathrm{HCl}(\mathrm{pH} 8.3), 1.5 \mathrm{mM} \mathrm{MgCl}_{2}, 20 \mu \mathrm{mol} \mathrm{dNTP}, 0.2 \mu \mathrm{Ci}$ of $\left[\alpha-{ }^{32} \mathrm{P}\right] \mathrm{dCTP}(3000 \mathrm{mCi} / \mathrm{mL}: 1.0 \mathrm{mCi}=37 \mathrm{Mbq})$, and $0.1 \mathrm{U}$ of AmpliTaq Gold polymerase (Perkin-Elmer, Norwalk, CT). Amplification of CPTI, HADHA, ICD, MMD, UCP3s, and UCP31 cDNA required a different ratio of rhodopsin DNA primers to target DNA primers because of variation in target DNA secondary structure as well as differences in relative abundance. To determine reaction conditions when both amplicons were simultaneously produced exponentially, we reverse transcribed and amplified serial dilutions of rat RNA with standard amounts of retinal RNA under different conditions and cycle numbers. Once optimal conditions were determined, we ran a single standard serial dilution with each quantification to regularly verify parallel production of both rat and bovine PCR products. This standard serial dilution consisted of cDNA reverse transcribed from $0.5,1.0$, and $2.0 \mu \mathrm{g}$ of rat skeletal muscle control RNA, respectively, and $0.01 \mu \mathrm{g}$ of bovine retinal RNA. Reactions were replicated three times once optimal PCR conditions were determined, and the primer concentrations were identical between study groups for each rat DNA target, respectively.

PCR amplification was carried out under the following conditions: one initial denaturation cycle of $94^{\circ} \mathrm{C}$ for 9 min, 35 cycles of denaturation at $94^{\circ} \mathrm{C}$ for $1 \mathrm{~min}$, annealing at $55^{\circ} \mathrm{C}$ for $1 \mathrm{~min}$, and extension at $72^{\circ} \mathrm{C}$ for $1 \mathrm{~min}$. A final extension at $72^{\circ} \mathrm{C}$ for 10 min completed the amplification. The PCR products were separated on a nondenaturing 5\% acrylamide gel, and the radioactivity incorporated into the amplified product was quantified using a phosphorimager and Molecular Analyst software (Bio-Rad Laboratories, Hercules, CA, U.S.A.). The relative abundance of CPTI, HADHA, ICD, MMD, UCP3s, and UCP31 was quantified relative to that of a control rhodopsin band from the same reaction, which was assigned an arbitrary level of unity. To determine the specificity of the primers, the amplified products were sequenced.

RT-PCR for AdipoQ. RT-PCR was performed upon the skeletal muscle samples described above with primers to the AdipoQ mRNA to demonstrate that samples were not contaminated with mature adipocytes (Table 1) (24). AdipoQ is an adipose-specific transcript that is expressed in mice, rats, and humans. White adipose tissue was used as positive control. This was particularly important for the assessment of skeletal muscle triglycerides because adipose tissue contamination can increase variability.

Mitochondrial isolation. Hind-limb skeletal muscle from three animals was batched per litter for an $n=1$ to prepare mitochondria for the enzyme assays described below; total $n=$ 6 litters for both IUGR and control. Mitochondria were isolated from skeletal muscle as described by Trounce et al. (25). Skeletal muscle was placed in ice-cold isolation buffer that consisted of $210 \mathrm{mM}$ mannitol, $70 \mathrm{mM}$ sucrose, $1 \mathrm{mM}$ EGTA, $0.5 \%$ (wt/vol) BSA (fatty acid free), and $5 \mathrm{mM}$ HEPES, $\mathrm{pH}$ 7.2. One gram of muscle was minced with a pair of fine scissors and homogenized in $10 \mathrm{~mL}$ of isolation buffer. The homogenate was centrifuged at $1500 \mathrm{~g}$ for $5 \mathrm{~min}$ at $4^{\circ} \mathrm{C}$. The supernatant was decanted and the centrifugation was repeated.

The subsequent supernatant was then centrifuged at $8000 \mathrm{~g}$ for $15 \mathrm{~min}$ at $4^{\circ} \mathrm{C}$. The resultant pellet was then suspended in ice-cold isolation buffer, and the high-speed centrifugation was repeated. The pellet was then washed and suspended in $200 \mu \mathrm{L}$ of isolation buffer. Mitochondrial protein determination was performed on a $30-\mu \mathrm{L}$ aliquot that again underwent high-speed

Table 1. Sequence of PCR primers

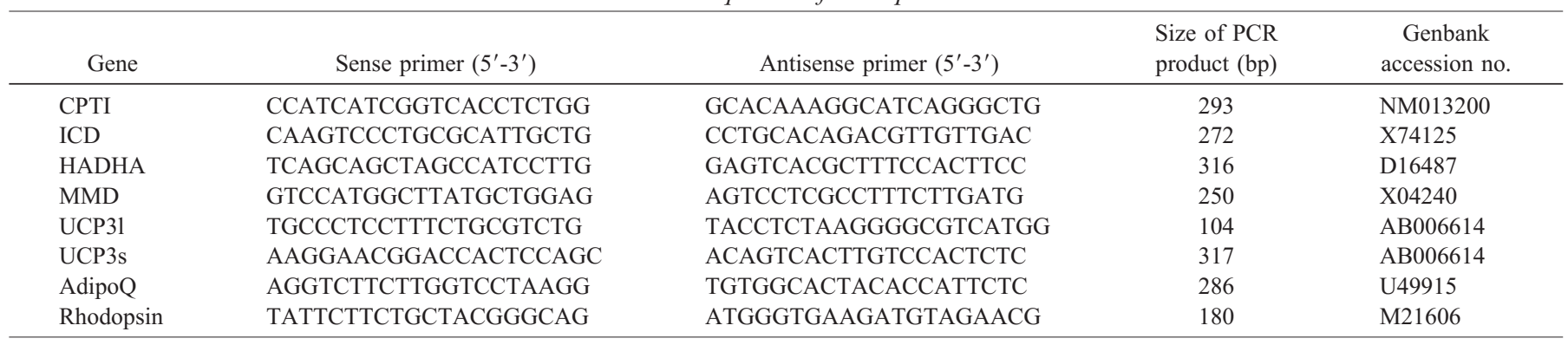

Sequences of each primer pair and their location in sequences cited in GenBank as noted. 
centrifugation for $15 \mathrm{~min}$ and was subsequently suspended in isolation buffer without BSA.

Evaluation of mitochondrial preparation. To evaluate the mitochondrial preparations, we performed aldolase (a cytoplasmic enzyme), catalase (a peroxisomal enzyme), ICD, and HADH assays upon the initial homogenate and the final mitochondrial pellet suspension each time we isolated mitochondria upon control samples of adult skeletal muscle. Successful performance of the mitochondrial isolation procedure should result in decreased aldolase and catalase activity and increased ICD and HADH activity in the mitochondrial pellet suspension versus the homogenate.

Aldolase assay. Aldolase activity was measured in adult skeletal muscle control sample homogenate and mitochondrial suspension using a commercial kit from Sigma Chemical Co. Diagnostics (St. Louis, MO, U.S.A.). A blank was performed with each experiment. Results were evaluated within the context of a calibration curve that was constructed per the instructions from Sigma Chemical Co. Diagnostics using the aldolase calibration solution and standardized by protein content.

Catalase assay. Catalase activity was measured in adult skeletal muscle control sample homogenate and mitochondrial suspension. Catalase activity was determined as reported by Lattari et al. (26) and is based upon the consumption of hydrogen peroxide. Briefly, $100 \mu \mathrm{L}$ of supernatant or mitochondrial pellet, respectively, were mixed with a reaction mixture that contained $50 \mathrm{mM}$ tris $\mathrm{HCl}(\mathrm{pH} \mathrm{7.4)}$ and $10 \mathrm{mM}$ hydrogen peroxide. The decrease in absorbance was at $240 \mathrm{~nm}$ in a spectrophotometer, and activity was calculated using the reported value for the extinction coefficient of hydrogen peroxide. Results were standardized by protein content of the sample solutions.

ICD assay. ICD activity was measured in isolated mitochondria pellet suspension from d 21 control and IUGR skeletal muscle ( $n=6$ each), as well as in adult control skeletal muscle homogenate and mitochondrial suspension using a commercial kit from Sigma Chemical Co. Diagnostics. Results were standardized by protein content of the sample solutions. Serial dilutions were performed to confirm reliability of the assay.

$\boldsymbol{H} \boldsymbol{A D H}$ assay. HADH activity was measured in isolated mitochondria pellet suspension from d 21 control and IUGR skeletal muscle ( $n=6$ each), as well as in adult control skeletal muscle homogenate and mitochondrial suspension. We adapted the assay described by Venizelos et al. (27) to measure the reverse reaction of $\mathrm{HADH}$. The reverse reaction detects more activity per milligram of protein and avoids the initial step/enzyme of $\beta$-oxidation, which is not part of HADH's repertoire (long-chain acyl-CoA dehydrogenase). This assay of skeletal muscle mitochondrial lipid oxidation-reduction also avoids confounding variables such as peroxisomal oxidation and transport of fatty acids from the plasma membrane to the mitochondria. High concentrations of NADH, myristoyl-CoA (C14), and acetyl-CoA drive the reaction. HADH activity is highest for carbon lengths $\mathrm{C} 12-16$. The reaction is quantified by following the decrease in NADH absorbance at $340 \mathrm{~nm}$.

The assay mixture contained $100 \mu \mathrm{M}$ NADH, $50 \mathrm{mM}$ 2-(N-morpholino)ethanesulfonic acid, $100 \mathrm{mmol}$ potasium phosphate, $0.1 \% \mathrm{wt} / \mathrm{vol}$ Triton X-100, $50 \mu \mathrm{M}$ acetyl-CoA, and
$200 \mu \mathrm{M}$ myristoyl-CoA. The reaction was initiated by adding $50 \mu \mathrm{L}$ of mitochondrial suspension. Results were standardized by protein content, and serial dilutions were performed to confirm reliability of the assay.

Skeletal muscle triglycerides. Tissue was homogenized in 1 $\mathrm{mL}$ of cold methanol with butylated hydroxyanisole $(5 \mathrm{mg} / \mathrm{mL})$ as an antioxidant. The methanol homogenate was mixed with 2 $\mathrm{mL}$ of chloroform and lipids were extracted using the method of Folch et al. (28). The triacylglycerols were isolated by high-performance thin-layer chromatography with silica gel G plates. The mobile phase was hexane-diethyl ether-formic acid (80:20:2 by volume). Spots of triacylglycerols were scraped off the silica gel plates. Lipids were extracted from silica gel by a mixture of chloroform-methanol-water $(5: 5: 1$ by volume) and the hydrolyzed with ethanolic potassium hydroxide (29). Glycerol, which is stoichiometrically equivalent to triacylglycerol, was measured enzymatically using Sigma Chemical Co. kit 320-A (glycerolkinase assay) with HPLC detection of NADH oxidation. In the end point, to the reaction mixture was added $10-\mathrm{mM}$ solution of hydrazine plus $30 \mathrm{mM}$ 2-amino-2-methyl-1-propanol in methanol to final methanol concentration $60 \%$ (vol/vol). The samples were centrifuged at $45,000 \times g$ for $5 \mathrm{~min}$ in a Heraeus Stratos Biofuge (Kendro Laboratory Products, GmbH, Hanau, Germany). Aliquots of supernatant $(10 \mathrm{~mL})$ were injected onto a $\mathrm{C}-18$ reverse phase column (HP Hypersil (Thermol Hypersil, Chesire, England), 5 $\mathrm{mm}, 100 \times 4.6 \mathrm{~mm})$. The column was eluted by a mobile phase composed of $0.2 \mathrm{M} \mathrm{KH}_{2} \mathrm{PO}_{4}(\mathrm{pH} 6.0), 2 \mathrm{mM}$ tetrabutylammonium- $\mathrm{OH}$ as an ion-paring reagent, and 14\% methanol. The flow rate was $1 \mathrm{~mL} / \mathrm{min}$. A Shimadzu LC-100AT vp HPLC equipped with a fluorescence detector (model RF10Axl) and an autosampler (model SIL-10AD vp, Shimadzu, Columbia, MD, U.S.A.) was used. Chromatograms were processed and stored in digital form with Class-VP software (Shimadzu, Columbia, MD, U.S.A.). A calibration curve was obtained by plotting the peak areas against amounts of NADH. The HPLC separation with fluorescence detection allows a direct estimation of the concentration of NADH in the reaction mixture with a very high sensitivity and without interference by other components. The signal from the HPLC fluorescent detector is linear from 2 to $200 \mathrm{pmol}$ of injected NADH.

Statistics. All data are expressed as a mean \pm SEM. ANOVA was determined (Fisher's protected least significance difference). The comparisons of the enzyme assays and skeletal muscle triglycerides were performed using the $t$ test. The analysis for RT-PCR was done using the nonparametric Wilcoxon matched pair test.

\section{RESULTS}

$\boldsymbol{m} \boldsymbol{R} \boldsymbol{N} \boldsymbol{A}$ levels at d 21 of life. AdipoQ expression was not detected in our skeletal muscle samples at $d 21$, and the appropriately sized 286-bp band was seen in the control white adipose tissue (Fig. 2).

To demonstrate the efficacy of our serial dilutions, we ran single standard serial dilution with each quantification of each enzyme to regularly verify parallel production of both rat and bovine PCR products with cDNA synthesized from $0.5,1.0$, 


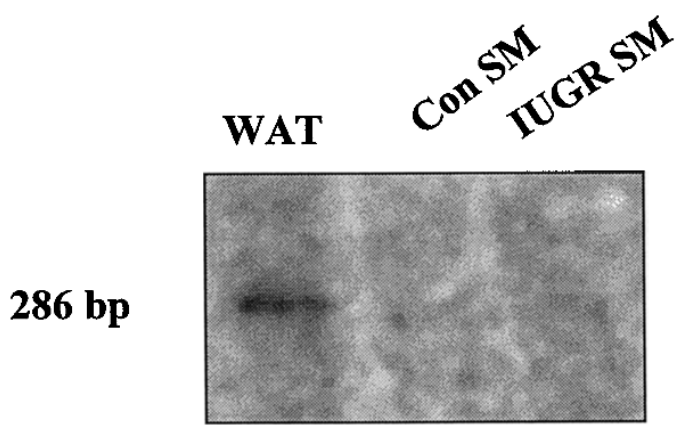

Figure 2. Representative phosphorimage AdipoQ in white adipose (WAT), control skeletal muscle (Con SM), and IUGR skeletal muscle (IUGR SM). AdipoQ band is 286 bp in size.

and $2.0 \mu \mathrm{g}$ of rat skeletal muscle control RNA, respectively, and $0.01 \mu \mathrm{g}$ of bovine retinal RNA. If the "standard" reaction using $1.0 \mu \mathrm{g}$ of rat RNA is assigned a value of unity, then the former and latter dilutions should result in values of 0.5 and 2.00 , respectively. There was no statistical difference between the predicted values and the actual values for each enzyme's PCR product (Table 2).

mRNA levels of CPTI, HADHA, ICD, and MMD were quantified in skeletal muscle from d 21 control and IUGR rat pups (preweaning) (Fig. 3). Gene expression of CPTI and HADH in IUGR skeletal muscle were increased to $212 \pm 14 \%$ and $208 \pm 9 \%$ ( $p<0.05$ for each) of control values, respectively. In contrast, gene expression of ICD and MMD were unchanged.

Segments of rat UCP3 mRNA that correspond to the short and long UCP3 isoforms in human were also quantified at d 21 of life. (Fig. 4). mRNA levels of both UCP3s and UCP31 were significantly elevated in IUGR skeletal muscle to $188 \pm 26 \%$ and $215 \pm 22 \%$ ( $p<0.05$ for each) of control values. There was no significant difference in levels of expression between the two isoforms. No sex differences were noted at this age for all five genes.

Enzyme assays at d 21 of life. Aldolase, catalase, ICD, and HADH assays were performed on the homogenate and the final mitochondrial suspension in adult skeletal muscle to demonstrate the veracity of our mitochondrial preparation. Activity of aldolase (a cytoplasmic enzyme) and catalase (a peroxisomal enzyme) decreased to approximately $10 \%$ of the initial supernatant's activity in the mitochondrial pellet suspension; in contrast, activity of HADH and ICD in the mitochondrial pellet suspension increased to approximately $2000 \%$ and $5000 \%$ of the supernatant's activity, respectively (Fig. 5).

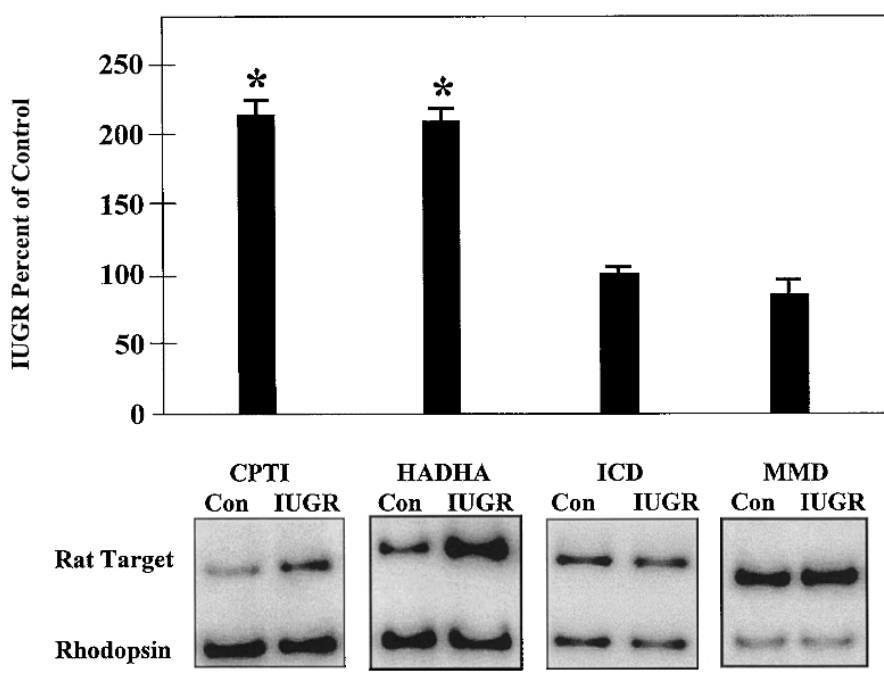

Figure 3. Quantification and representative phosphorimages of CPTI, HADHA, ICD, and MMD RT-PCR products in control (Con) and IUGR juvenile d 21rat skeletal muscle. Rat targets and internal control (rhodopsin) RT-PCR products were quantified by phosphorimage analysis (Molecular Analyst software, Bio-Rad). Results are expressed as IUGR mean percentage of control $\pm \operatorname{SEM}(* p<0.05)$.

HADH and ICD assays were performed on d 21 IUGR and control skeletal muscle. Similar to mRNA levels, HADH function was significantly increased to approximately $170 \%$ of control values in IUGR skeletal muscle $(1.07 \pm 0.10 \mathrm{nmol} /$ $\mathrm{min} / \mathrm{mg}$ protein versus $1.72 \pm 0.12 \mathrm{nmol} / \mathrm{min} / \mathrm{mg}$ protein $)(p<$ $0.05)$. In contrast, ICD function was similar between control and IUGR mitochondria.

Skeletal muscle triglycerides at d 21 of life. Skeletal muscle triglycerides were quantified in d 21 control and IUGR skeletal muscle using HPLC. Triglyceride levels were significantly increased in IUGR skeletal muscle $(113.9 \pm 33.6 \mu \mathrm{mol} / \mathrm{g}$ wet weight $)(p<0.05)$ compared with control skeletal muscle $(15.5 \pm 6.6 \mu \mathrm{mol} / \mathrm{g}$ wet weight $)(p<0.05)$.

\section{DISCUSSION}

The present study finds increased mRNA levels of CPTI, UCP3, and HADHA mRNA and increased HADH function in d 21 IUGR skeletal muscle. These new findings are significant because they demonstrate molecular mechanisms that link the altered in utero environment of uteroplacental insufficiency and the altered metabolism observed in IUGR neonates (2-6). The molecular mechanisms suggested by our findings may contribute to increased energy expenditure and oxygen con-

Table 2. Standard serial dilutions vs. "standard" $1.0 \mu \mathrm{g}$ rat $R N A / 0.01 \mu \mathrm{g}$ bovine retinal RNA defined as 1.0

\begin{tabular}{lcc}
\hline Enzyme & $\times 0.5(0.5 \mu \mathrm{g}$ rat RNA $/ 1.0 \mu \mathrm{g}$ bovine retinal RNA $)$ & $\times 2(0.5 \mu \mathrm{g}$ rat RNA/0.01 $\mu \mathrm{g}$ bovine retinal RNA $)$ \\
\hline CPTI & $0.52 \pm 0.06$ & $2.10 \pm 0.09$ \\
ICD & $0.54 \pm 0.04$ & $2.05 \pm 0.07$ \\
HADHA & $0.47 \pm 0.05$ & $1.93 \pm 0.10$ \\
MMD & $0.57 \pm 0.08$ & $2.20 \pm 0.12$ \\
UCP31 & $0.55 \pm 0.06$ & $2.22 \pm 0.13$ \\
UCP3s & $0.52 \pm 0.03$ & $2.13 \pm 0.08$ \\
\hline
\end{tabular}

Values are the average of the three replicate reactions performed once optimal PCR conditions were determined \pm SEM. 


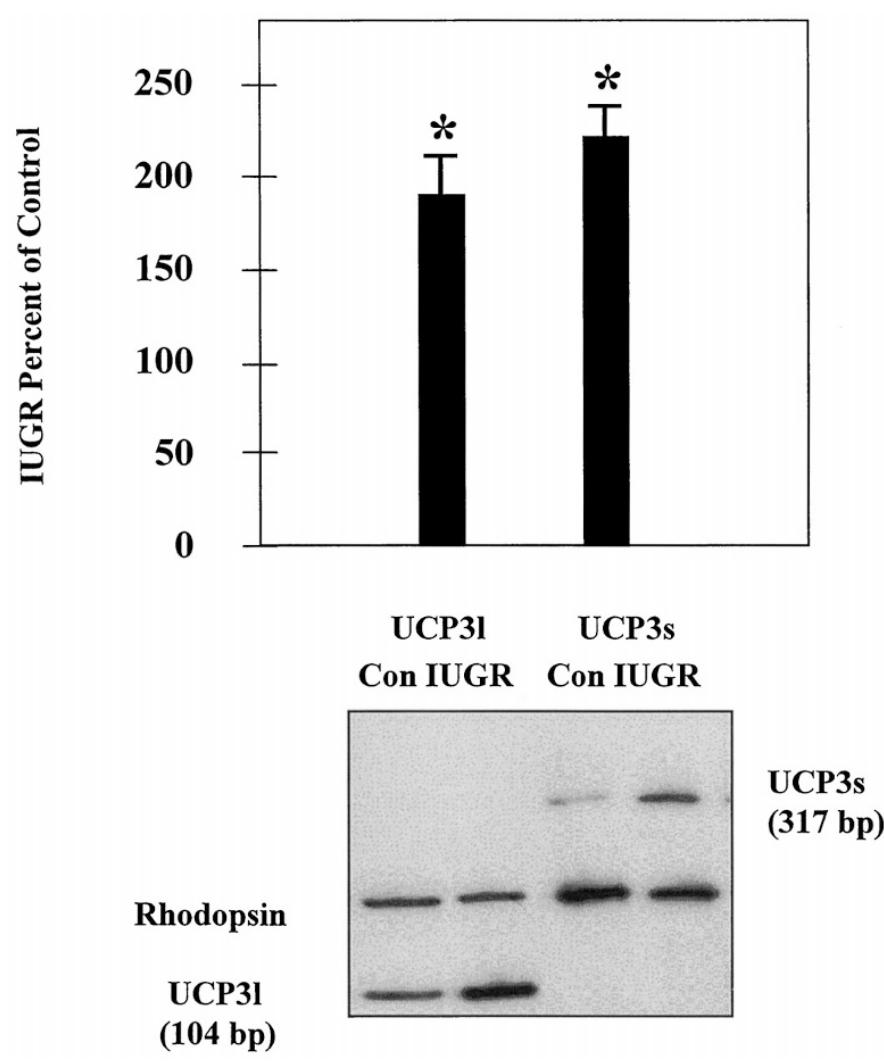

Figure 4. Quantification and representative phosphorimages of UCP31 and UCP3s RT-PCR products in control (Con) and IUGR juvenile d 21 rat skeletal muscle. Rat targets and internal control (rhodopsin) RT-PCR products were quantified by phosphorimage analysis (Molecular Analyst software, BioRad). Results are expressed as IUGR mean percentage of control $\pm \operatorname{SEM}\left({ }^{*} p<\right.$ $0.05)$.

sumption because oxygen consumption and oxygen/ATP ratio increases in parallel with mitochondrial $\beta$-oxidation (30).

Our findings of increased HADHA mRNA and HADH function are intriguing considering our previous findings of decreased gene expression of a complex I component and a decreased mitochondrial $\mathrm{NAD}^{+} / \mathrm{NADH}$ ratio (7). HADH function causes a gradual and slight decline in the $\mathrm{NAD}^{+} / \mathrm{NADH}$ ratio in skeletal muscle mitochondria, and lowering $\mathrm{NAD}^{+} /$ NADH ratio reduces the Krebs cycle flux (31). One of the steps that contributes to this reduction is product inhibition of ICD by NADH (32). The relationship between the Krebs cycle dehydrogenases and $\mathrm{NAD}^{+} / \mathrm{NADH}$ ratio is important because of the physical proximity and interaction of these enzymes with complex I (33). The increased skeletal muscle expression and function of $\mathrm{HADH}$ may compensate for the reduction in mitochondrial $\mathrm{NAD}^{+} / \mathrm{NADH}$ and complex I expression, and allow HADH to effectively compete with the Krebs cycle dehydrogenases.

Coordinate expression of HADH and CPTI has not been previously demonstrated under specific physiologic conditions, though clues exist that link expression and function of these enzymes to similar effects upon intercellular physiology and intracellular biochemistry. Fetal deficiency of either CPTI or HADH alters in utero intercellular physiology and may present as maternal acute fatty liver of pregnancy, and isolated fractions of intracellular malonyl-CoA sensitive CPT contain a $\beta$-oxidation enzyme with activities consistent with HADH (34-36). CPTI is an important regulator of skeletal muscle fatty acid oxidation that is inhibited by malonyl-CoA. Increased HADH function and mitochondrial $\beta$-oxidation lower malonyl-CoA levels during hyperinsulinemia and may therefore be connected to CPTI function (37). However, several questions remain unanswered about the regulation of CPTI and malonyl-CoA in skeletal muscle, including the significance of intracellular compartmentalization and other malonyl-CoAconsuming enzymes (38).

Despite increased CPTI gene expression and HAHA gene expression and function, IUGR skeletal muscle at $\mathrm{d} 21$ contains more triglycerides than muscle from sham-operated controls. Other investigators have found that skeletal muscle triglycerides and/or skeletal muscle triglyceride synthesis can correlate positively with lipid oxidation in both mature humans and rats, and the substrate fueling the increased lipid oxidation in these situations is predominately plasma FFA (39-43). Plasma FFA may be derived from diet or from hepatic synthesis. The high-fat diet of the preweaning rat pup provides an ample lipid source to fuel increased mitochondrial lipid oxidation; furthermore, expression of acetyl-CoA carboxylase, the rate-limiting enzyme of hepatic fatty acid synthesis, is increased in the liver of the 21-d-old IUGR preweaning rat pups (19). We speculate that, at this age, an equilibrium is reached between increased hepatic synthesis and increased skeletal muscle mitochondrial lipid oxidation, which subsequently results in only a modest increase in plasma triglycerides (19).

Skeletal muscle triglyceride accumulation is also likely a result of plasma fatty acid uptake and esterification because rat skeletal muscle contains minute amounts of fatty acid synthase (37). Skeletal muscle triglycerides have been positively correlated with insulin resistance $(44,45)$. Moreover, Kelley et al. (20) found increased skeletal muscle triglycerides and failure to suppress lipid oxidation in the skeletal muscle of adult obese insulin resistant individuals. The accumulation of skeletal muscle triglycerides and increased $\beta$-oxidation machinery in this study indicates a persistent dysregulation that could contribute to the altered metabolism seen in IUGR mature individuals.

Skeletal muscle $\beta$-oxidation correlates positively with UCP3 expression, and it has been proposed that the stimulatory effects of $\beta$-oxidation upon gene expression could involve intermediary products (46). Although the function of skeletal muscle UCP3 is still controversial, studies of UCP3 knockout mice indicate that UCP3 has uncoupling activity and its expression negatively correlates with mitochondrial free radical production (47). Our finding of increased UCP3 expression suggests a mechanism through which oxygen and mitochondrial lipid oxidation are increased while ATP production and subsequent growth are decreased.

IUGR rats at d 21 do not demonstrate abnormal prefasting and 24-h fasting levels of glucose, insulin, and glucagon levels. Our findings of altered skeletal muscle gene expression and function occur long after the initial insult and may be an example of Barker's "fetal origins hypothesis" (1). This hypothesis proposes that fetal adaptation to a deprived intrauterine milieu leads to permanent changes in gene expression, cellular biology, and whole body physiology. These adapta- 


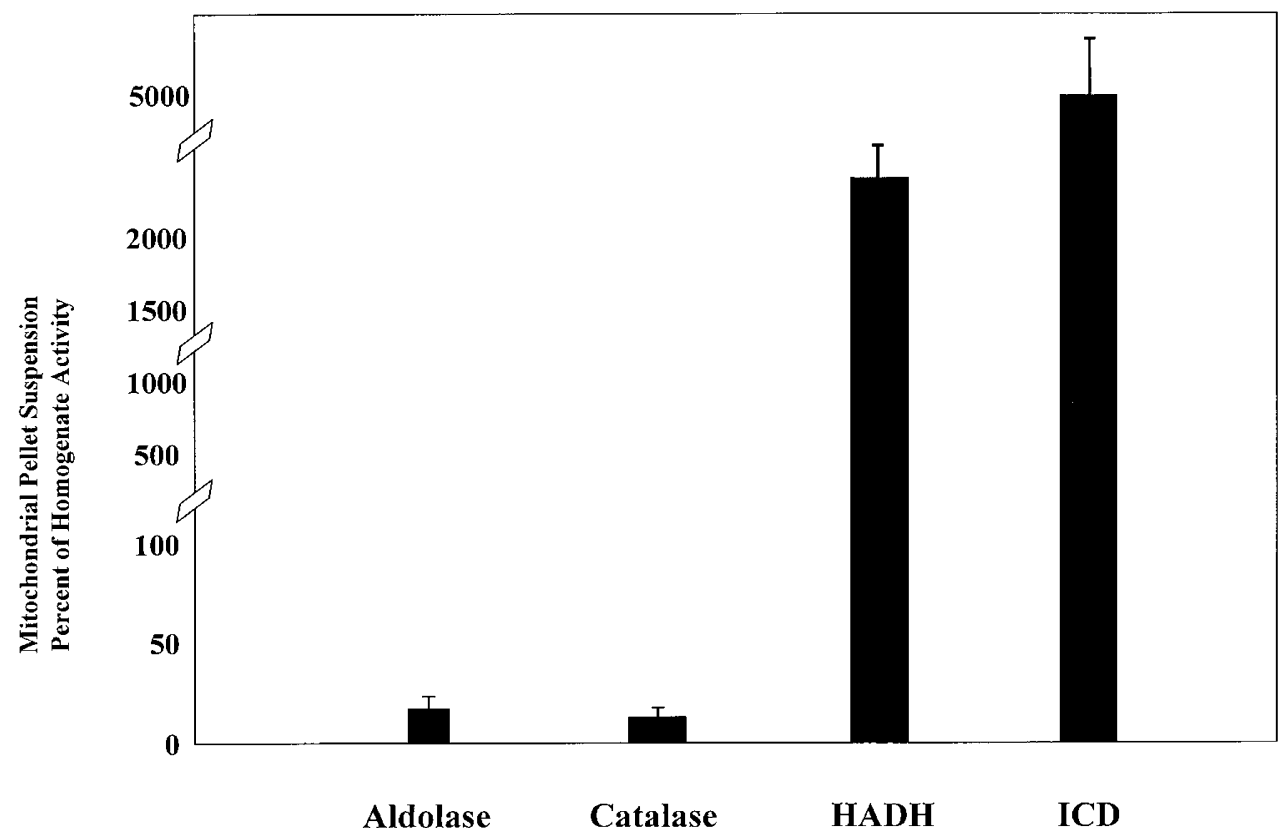

Figure 5. Activity of aldolase, catalase, HADH, and ICD in homogenate and final mitochondrial pellet suspension. Results are expressed for enzyme activity of the final mitochondrial pellet as the percent \pm SEM of homogenate activity for each enzyme.

tions ensure the survival of the immature animal under adverse conditions, but may be detrimental to the adult. The adaptations observed in this study may be beneficial by leading to increased skeletal muscle mitochondrial lipid oxidation and subsequently sparing glucose in deference to the relatively large brain of the IUGR neonate.

Caution is necessary of course when attempting to apply data from a rat model to human pathophysiology. The fetal and juvenile rat is physiologically immature relative to the human, and the insult imposed on the fetal rat in this model of uteroplacental insufficiency is severe and specific. Furthermore, the laboratory rat in this study is inbred and experiences a homogeneous diet and environment. In contrast, the timing and impact of uteroplacental insufficiency experienced by humans range across a continuum, and the human life experience is confounded by both genetic and environmental variables.

In summary, we find that uteroplacental placental insufficiency and subsequent IUGR causes alterations in $\mathrm{d} 21$ skeletal muscle gene expression and function in proteins involved in mitochondrial $\beta$-oxidation. These changes provide a molecular mechanism that could contribute to the poor growth, increased oxygen consumption, and altered lipid metabolism observed in the IUGR infant.

Acknowledgment. The authors thank Dr. Sherin Devaskar for her support and guidance.

\section{REFERENCES}

1. Barker DJP 1997 Maternal nutrition, fetal nutrition, and disease in later life. Nutrition 13:807-813

2. Davies PSW, Clough H, Bishop NJ, Lucas A, Cole JJ, Cole TJ 1996 Total energy expenditure in small for gestational age infants. Arch Dis Child 74:F208-F210

3. Bohler T, Kramer T, Janecke AR, Hoffmann GF, Linderkamp O 1999 Increased energy expenditure and fecal fat excretion do not impair weight gain in small for gestational age preterm infants. Early Hum Dev 54:223-234
4. Scopes JW, Ahmed I 1966 Minimal rats of oxygen consumption in sick and premature newborn infants. Arch Dis Child 41:407-416

5. Sinclair JC, Silverman WA 1966 Intrauterine growth in active tissue mass of the human fetus, with particular reference to the undergrown baby. Pediatrics $38: 48-62$

6. Chessex P, Reichman B, Verellen G, Putet G, Smith JM, Heim T, Swyer PR 1984 Metabolic consequences of intrauterine growth retardation in very low birth weight infants. Pediatr Res 18:709-713

7. Lane RH, Chandorkar AK, Flozak AS, Simmons RA 1998 Intrauterine growth retardation alters mitochondrial gene expression and function in fetal and juvenile rat skeletal muscle. Pediatr Res 43:563-570

8. Eaton S, Bartlett K, Pourfarzam M 1999 Intermediates of myocardial mitochondrial $\beta$-oxidation: possible channelling of NADH and CoA esters. Biochim Biophys Acta $1437: 402-408$

9. Eaton S, Bursby T, Middleton B, Pourfarzam M, Mills K, Johnson AS, Bartlett K 2000 The mitochondrial trifunctional protein: center of a $\beta$-oxidation metabolon. Biochem Soc Trans 28:177-182

10. Eaton S, Bartlett K, Pourfarzam M 1996 Mammalian mitochondrial $\beta$-oxidation. Biochem J 320:345-357

11. Salway JG 1994 Metabolism at a Glance. Blackwell Scientific, Oxford, pp 72-75

12. Boss O, Hagen T, Lowell BB 2000 Uncoupling proteins 2 and 3 potential regulators of mitochondrial energy metabolism. Diabetes 49:143-156

13. McGarry JD, Brown NF 1997 The mitochondrial carnitine palmitoyltransferase system. Eur J Biochem 244:1-14

14. Boss O, Samec S, Paoloni-Giacobino A, Rossier C, Dulloo A, Seydoux J, Muzzin P, Giacobino JP 1997 Uncoupling protein-3: a new member of the mitochondrial carrier family with a tissue specific expression. FEBS Lett 408:39-42

15. Samec S, Seydoux J, Dulloo AG 1999 Skeletal muscle UCP3 and UCP2 gene expression in response to inhibition of free fatty acid flux through mitochondrial $\beta$-oxidation. Eur J Physiol 438:452-457

16. Ogata ES, Bussey ME, Finley S 1985 Altered gas exchange, limited glucose and branched chain amino acids and hypoinsulinism retard fetal growth in the rat. Metabolism 35:970-977

17. Unterman TG, Simmons RA, Glick RP, Ogata ES 1993 Circulating levels of insulin, insulin-like growth factor-I (IGF-I), IGF-II, and IGF-binding proteins in the small for gestational age fetal rat. Endocrinology 132:327-336

18. Ogata ES, Bussey ME, LaBarbera A, Finley S 1985 Altered growth, hypoglycemia, hypoalaninemia, and ketonemia in the young rat: postnatal consequences of intrauterine growth retardation. Pediatr Res 19:32-37

19. Lane RH, Kelley DE, Gruetzmacher EM, Devaskar SU 2001 Uteroplacental insufficiency alters hepatic fatty acid-metabolizing enzymes in juvenile and adult rats. Am J Physiol 280:R183-R190

20. Kelley DE, Goodpaster B, Wing RR, Simoneau JA 1999 Skeletal muscle fatty acid metabolism in association with insulin resistance, obesity, and weight loss. Am J Physiol 277: E1130-1141

21. Chomczynski P, Sacchi N 1987 Single step method of RNA isolation by acid guanidinium thiocyanate-phenol-chloroform extraction. Anal Biochem 162:156-159 
22. Lane RH, Flozak AS, Simmons RA 1996 Measurement of GLUT mRNA in liver of fetal and neonatal rats using a novel method of quantitative polymerase chain reaction. Biochem Mol Med 59:192-199

23. Lane RH, Crawford SE, Flozak AS, Simmons RA 1999 Localization and quantification of glucose transporters in liver of growth retarded fetal and neonatal rats Am J Physiol 276: E135-E142

24. Hu E, Liang P, Spiegelman BM 1996 AdipoQ is a novel adipose-specific gene dysregulated in obesity. J Biol Chem 271: 10697-10703

25. Trounce IA, Kim YL, Jun AS, Wallace DC 1996 Assessment of mitochondria oxidative phosphorylation in patient muscle biopsies, lymphoblasts, and transmitochondrial cell lines. In: Attardi GM, Chomyn A (eds) Methods in Enzymology: Mitochondrial Biogenesis and Genetics. San Diego, Academic Press, pp 485-491

26. Lattari A, Daood MJ, Sieck GC, Watchko JF 1997 Rat diaphragm oxidative capacity, antioxidant enzymes, and fatigue: newborn versus adult. Pediatr Res 42:60-65

27. Venizelos N, Ijlst L, Wanders RJ, Hagenfeldt L $1994 \beta$-oxidation enzymes in fibroblasts from patients with 3-hydroxdicarboxylic aciduria. Pediatr Res 36:111-114

28. Folch J, Lees M, Sloane-Stanley GH 1957 A simple method for the isolation and purification of total lipids from animal tissues. J Biol Chem 226:497-509

29. Frayn KN, Maycock PF 1980 Skeletal muscle tracylglycerol in the rat: methods for sampling and measurement, and studies of biological variability. J Lipid Res 21:131144

30. Mollica MP, Iossa S, Liverini G, Soboll S 1999 Stimulation of oxygen consumption following addition of lipid substrates in liver and skeletal muscle from rats fed a high-fat diet. Metabolism 48:1230-1235

31. Eaton S, Bhuiyan AKMJ, Kler RS, Turnball DM, Bartlett 1993 Intramitochondrial control of the oxidation of hexadecanoate in skeletal muscle. A study of acyl-CoA esters which accumulate during rat skeletal-muscle mitochondria beta-oxidation of [U-14C] hexadecanoate and [U-14C] hexadecanoyl-carnitine. Biochem J 289:161168

32. Williamson JR, Cooper RH 1980 Regulation of the citric acid cycle in mammalian systems. FEBS Lett 17:K73-K85

33. Porpaczy Z, Sumegi B, Alkonyi I 1987 Interaction between NAD-dependent isocitrate dehydrogenase alpha-ketoglutarate dehydrogenase complex and NADH: ubiquinone oxidoreductase. J Biol Chem 262:9509-9514

34. Ibdah JA, Bennett MJ, Rinaldo P, Zhao Y, Gibson B, Sims HF, Strauss AW 1999 A fetal fatty-acid oxidation disorder as a cause of liver disease in pregnant women. N Engl J Med 340:1723-1731
35. Innes AM, Seargeant LE, Balachandra K, Roe CR, Wanders RJ, Ruiter JP, Casiro O, Grewar DA, Greenberg CR 2000 Hepatic carnitine palmitoyltransferae I deficiency presenting as maternal illness in pregnancy. Pediatr Res 47:43-45

36. Kerner J, Bieber L 1990 Isolation of a malonyl-CoA-sensitive CPT/beta-oxidation enzyme complex from heart mitochondria. Biochemistry 29:4326-4334

37. Alam N, Saggerson ED 1998 Malonyl-CoA and the regulation of fatty acid oxidation in soleus muscle. Biochem J 334:233-241

38. Ruderman NB, Saha AK, Vavvas D, Witters LA 1999 Malonyl-CoA, fuel sensing, and insulin resistance. Am J Physiol 276: E1-E18

39. Dyck DJ, Miskovic D, Code L, Luiken JJFP, Bonen A 2000 Endurance training increases FFA oxidation and reduces triacylglycerol utilization in contracting rat soleus. Am J Physiol 278:E778-E785

40. Ebeling P, Essen-Gustavsson B, Tuominen JA, Koivisto VA 1998 Intramuscular triglyceride content is increased in IDDM. Diabetologia 41:111-115

41. Sreenan S, Keck S, Fuller T, Cockburn B, Burant CF 1999 Effects of troglitzaone on substrate storage and utilization in insulin resistant rats. Am J Physiol. 276 E1119E1129

42. Schrauwen P, Wagenmakers AJM, van Marken Lichtenblet WD, Saris WHM, Westerterp 2000 Increase in fat oxidation on a high-fat diet is accompanied by an increase in triglyceride-derived fatty acid oxidation. Diabetes 49:640-646

43. Yki-Jarvinen H, Puhakainen I, Saloranta C, Groop L, Taskinen MR 1991 Demonstration of a novel feedback mechanism between FFA oxidation from intracellular and intravascular sources. Am J Physiol 260:E680-E689

44. Dan PA, Lillioja S, Kriketos AD, Milner MR, Baur LA, Bogardus C, Jenkins AB, Storlien LH 1997 Skeletal muscle triglyceride levels are inversely related to insulin action. Diabetes 46:983-988

45. Perseghin G, Scifo P, De Cobelli FD, Pagliato E, Battezzati A, Arcelloni C, Vanzulli A, Testolin G, Pozza G, Maschio AD, Luzi L 1999 Intramyocellular triglyceride content is a determinant of an in vivo insulin resistance in humans. Diabetes 48:1600-1606

46. Muzzin P, Boss O, Giocobino JP 1999 Uncoupling protein-3: its possible biological roles and mode of regulation in rodents and humans. J Bioenerg Biomembr 31:467473

47. Vidal-Puig AJ, Grujic D, Zhang CY, Hagen T, Boss O, Ido Y, Szczepanik A, Wade J, Mootha V, Cortright R, Muoio DM, Lowell BB 2000 Energy metabolism in uncoupling protein 3 gene knockout mice. J Biol Chem 275:16258-16266 